\title{
WATER AVAILABILITY ASSESSMENT IN SHIPRA RIVER
}

\author{
K. Satish Kumar ${ }^{1}$, H.L. Tiwari ${ }^{2}$, R.V. Galkate ${ }^{3}$ \\ ${ }^{I}$ M. Tech Student, Department of Civil Engineering, Maulana Azad National Institute of Technology, Bhopal, INDIA \\ ${ }^{2}$ Assistant Professor, Department of Civil Engineering, Maulana Azad National Institute of Technology, Bhopal, \\ INDIA \\ ${ }^{3}$ Scientist, National Institute of Hydrology, Regional Centre, Bhopal, INDIA
}

\begin{abstract}
Water availability analysis was carried out in Ujjain Basin part of Shipra Basin located in Madhya Pradesh state, at various probabilities for different dependable flow volumes. The flow regime was analyzed in this study using Flow Duration curve technique and the model was developed using MIKE BASIN software. Through MIKE model was developed for the whole Shipra Basin, a diversion canal in the name of KHAN Diversion and Narmada-Shipra link is added. In this study the flow at Ujjain city is mainly influenced by Khan diversion which is developed in the model and Narmada-Shipra link. Three scenarios were developed and net flow to Ujjain city were studied and analyzed for Khumb Mela that is to be held in 2016. The water availability analysis was performed for the individual months. In the present study the availability of dependable flow volumes were calculated month wise at 70, 75, 80, 85, 90, 95 and 100\% probability of exceedance.
\end{abstract}

Key Words: water availability, flow duration curve, MIKE BASIN model, Khan Diversion, Narmada-Shipra link.

\section{INTRODUCTION}

In years to come, water, the need of life, is possibly to pose greatest challenge on account of its increased demand with population rise, economic development, and shrinking supplies due to over exploitation and pollution. In India, with development, the demand of water is increasing both in urban and rural areas. This may create increased tension and dispute between these areas for sharing and command of water resources.

The water availability study is carried out in Shipra river, particularly in Ujjain city. As the areas around Shipra River are developing domestically and industrially, there is a lack of water resources here. The Ujjain city is facing the problem of water scarcity in rural as well as in urban areas to meet various water demands. Mainly from Gambhir reservoir water is supplied to Ujjain city. Due to increase in population, industrial, Simhastha purposes the demand of water is increased. To fulfill all the requirements, water availability study is made.

The water availability analysis in Ujjain city is carried out by estimating dependable flow volumes at various probability levels using Flow Duration Curve technique. Assessment of dependable flows along with their distribution in time is essential for planning and development of water supply schemes. Especially the study of the lean season flow characteristics is important to determine the probability of the river system to provide adequate and assured water supply for meeting the expected demands (Pandey and Ramasastry, 2003) [1]. The time periods usually considered in flow duration analyses are 1 day, 7 days, 10 days or 30 days. The present study aims to assess the availability of dependable flows volumes in the Shipra River on monthly basis within a year at 70, 75, 80,
85,90 and $95 \%$ probability of exceedance from 1990 to 2006. (Chang and Boyer, 1977 [2] and Clausen and Pearson, 1995 [3]) The monthly Flow Duration Curves (FDC) for different months and for different scenarios (scenario1, 2, 3) was developed using MIKE BASIN and analyzed (Galkate et. al. 2010) [4].

\section{STUDY AREA}

Shipra is also known as Kshipra or Avanthinadi. The river originates at KakriBardi hill of Vindhya Range, $20 \mathrm{~km}$ South-East of Indore city near a small village Ujjani $22^{0}$ $31^{\prime}$ North and $76^{\circ}$ East. It flows north across the Malwa Plateau through Dewas, Indore and Gwalior districts of the state and joins Chambal river near Kalu-Kher village ( $23^{\circ} 53^{\prime} \mathrm{N}$ and $\left.75^{\circ} 31^{\prime \prime} \mathrm{E}\right)$. The overall course of the Shipra river is $190 \mathrm{Km}$ with a catchment area of $5600 \mathrm{~km}^{2}$. Main tributaries of Shipra are Khan River near Ujjain and Gambhir river near Mahidpur.

Shipra River is considered as sacred as Ganga by Hindus and the word Shipra is used as a symbol of purity or chastity or clarity of soul, emotion and body. Holy city of Ujjain is situated on the right bank river where Simhasta (Kumbh Mela) is held at every 12 years. Simhasta is the religious gathering of Hindus where they worship the river goddess Khipra and take holy dip in the river water to clean their souls.

Over the years river lost its perennial nature and now runs dry for a period of 5 to 6 months per year. Water of Shipra is used for drinking, industrial and irrigation purpose and the main land use along the river is agriculture. There are three small dams on Shipra River with total irrigation area of $3703 \mathrm{Km}^{2}$. These are Sahibkhedi near Ujjain (irrigated area $984 \mathrm{~km}^{2}$ ), Kazikhedi near Ujjain (irrigated area $1366 \mathrm{~km}^{2}$ ) 
and Dholavar in Ratlam district (irrigated area $1353 \mathrm{~km}^{2}$ ). The Shipra river basin is as shown in figure 1.

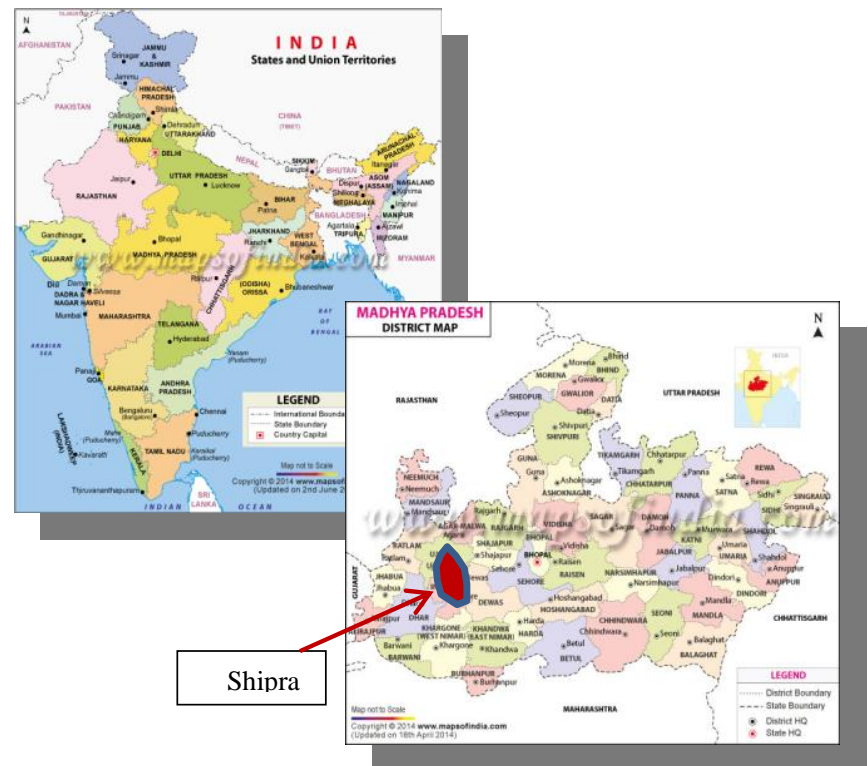

Figure 1: Index map showing location of Shipra basin in Madhya Pradesh.

\section{DATA AVAILABILITY}

To carry out the analysis various meteorological data such as rainfall, temperature, wind speed, humidity, sunshine hours, etc. and hydrological data such as runoff or discharge data is essential. This study has been carried out at National Institute of Hydrology (NIH), Regional Centre, Bhopal as a part of their research program thus data collected by NIH, Bhopal from various state and central government agencies was used in the study. The details of data collection and data availability are discussed in this section

\section{MIKE 11 NAM MODEL APPLICATIONS}

By using Mike Basin and Mike 11 NAM model, a wellequipped model is developed, DHI 2003 [5].

- Khan Diversion is added to the model, diverted from Pipliya Ragho village in Khan river to downstream of Kaliyadeh Palace in Shipra river.

- A Narmada-Shipra link is added to the Shipra River at Ujjaini Village from Narmada River. Different scenarios were developed and analyzed for Water Resource Planning and Management. The developed scenarios are

\subsection{Scenario1: Model With Neither Khan Diversion And Nor Narmada-Shipra Link.}

In the first scenario Mike Basin model is simulated without any links and diversions. As main study area is Ujjain City (node 8), results were analyzed to check the net flow to Ujjain City. Figure 2 gives the details about the model with scenario 1 features.

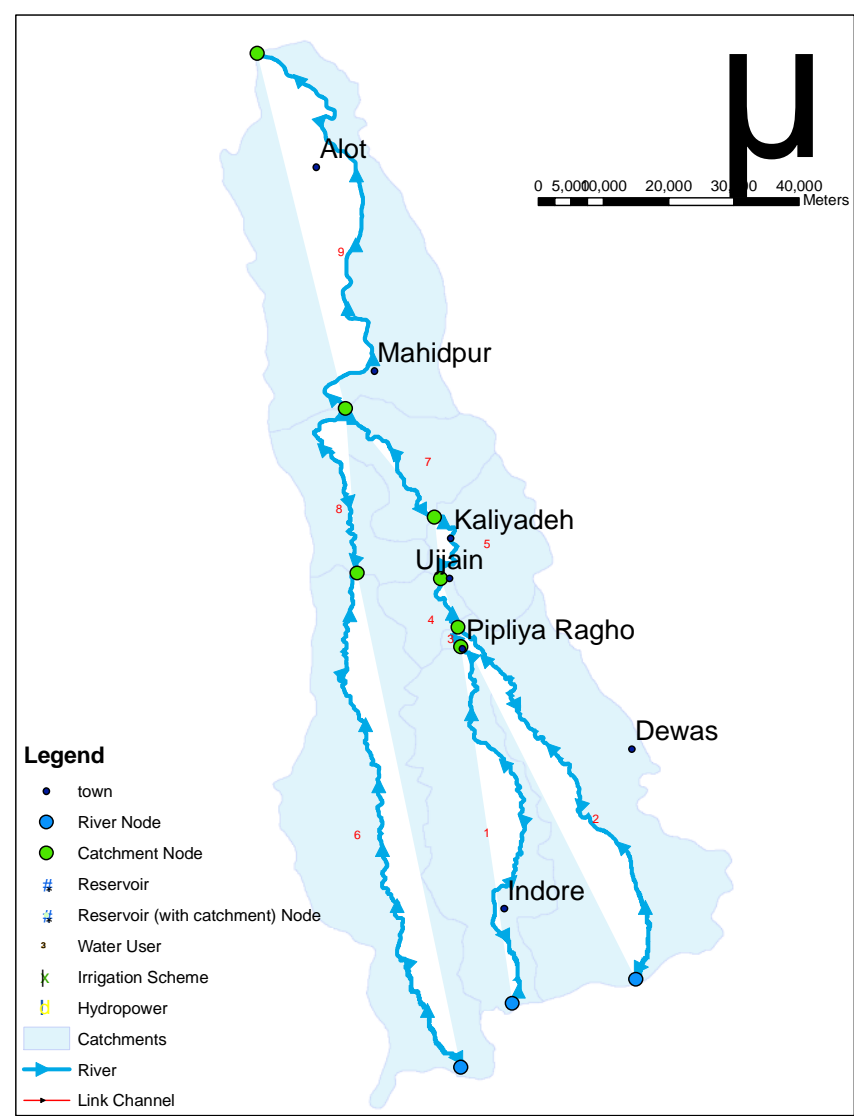

Figure 2: Model without Khan Diversion and NarmadaShipra link

\subsection{Scenario2: Model With Only Khan Diversion}

\section{But No Narmada-Shipra Link}

In the second scenario a diversion is made in Khan river. Dew to this whatever be the flow coming from Shipra river will be diverted and added back to Shipra river after Ujjain city as the water in Shipra river is polluted, can't be used at the time of Simhastha. The polluted water can be used for irrigation purpose. So a node is developed in the diverted river and water is supplied to the fields for irrigation. The flow is diverted in non-monsoon period only. In monsoon period precipitation occurs and Shipra water will be less polluted.

After adding an irrigation user, water is supplied at a rate of $5 \mathrm{~m}^{3} / \mathrm{s}$ in the non-monsoon period. There is no return flow from the irrigation user. Then results were compared in scenario1 and scenario 2. Mainly at Ujjain City (node 8) net flow is observed, as in the first case flow will be there but after adding a diversion, there won't be any flow in nonmonsoon period. The results were produced in the form of Flow duration curves and Hydrographs. Figure 3 gives the details about Khan Diversion. 


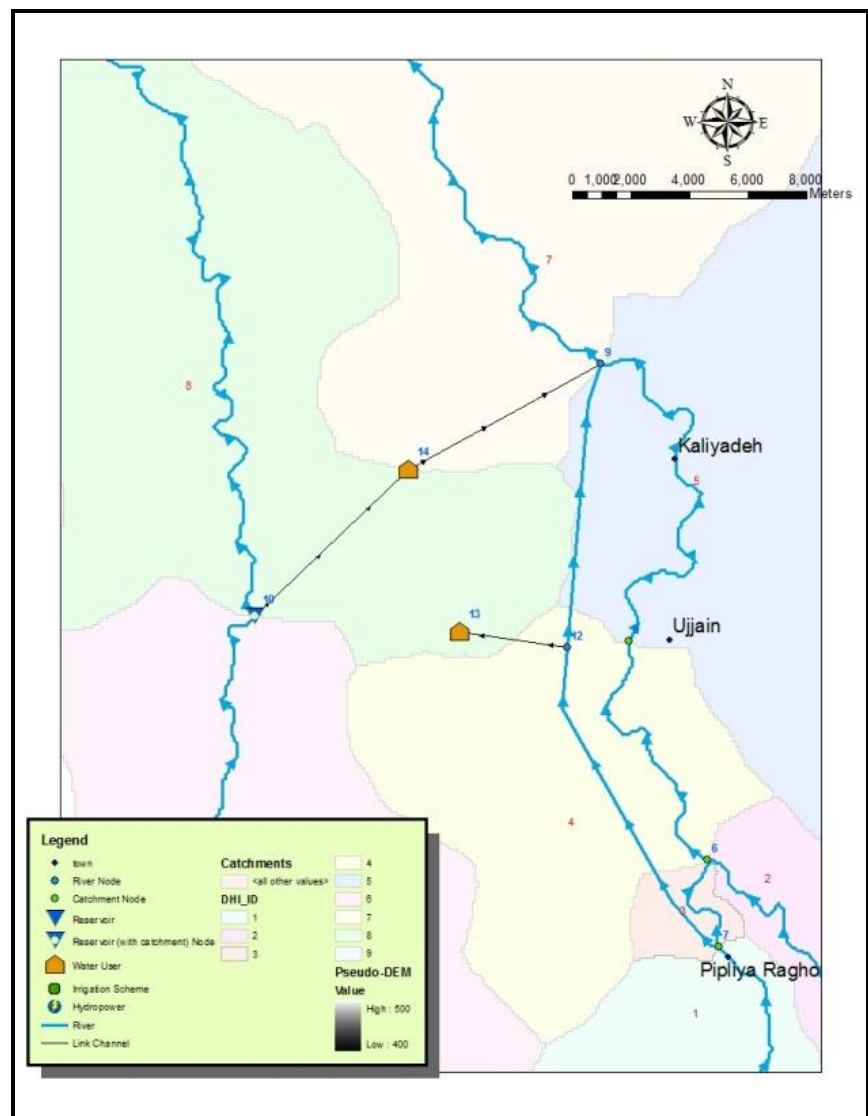

Figure 3: Scenario2: Model with only Khan Diversion but no Narmada-Shipra link

\subsection{Scenario3: Model With Khan Diversion And Narmada-Shipra Link.}

Along with Khan Diversion Narmada-Shipra link is added to the model. The link is added at Ujjaini village and a discharge of $2.5 \mathrm{~m}^{3} / \mathrm{s}$ is added to it in the non-monsoon period. Figure 4 shows the Narmada-Shipra link.

\section{WATER AVAILABILITY ANALYSIS}

Water availability analysis was carried out in Ujjain Basin at various probabilities for different dependable flow volumes. Flow Duration Curve technique was adopted in this study. Net flow to Ujjain (node8) of the three scenarios as explained in the previous chapters were transferred to an excel sheet. The water availability analysis was performed for the individual months. For example, in each and every year of simulation period only January data was separated and individual month water availability was calculated. By this one could easily know, what's happening in the particular months. In the present study the availability of dependable flow volumes were calculated month wise at 70 , $75,80,85,90,95$ and $100 \%$ probability of exceedance. The dependable flow $\left(\mathrm{m}^{3} / \mathrm{s}\right)$ values for different scenarios at various probability levels were presented in tables 1, 2 and 3.

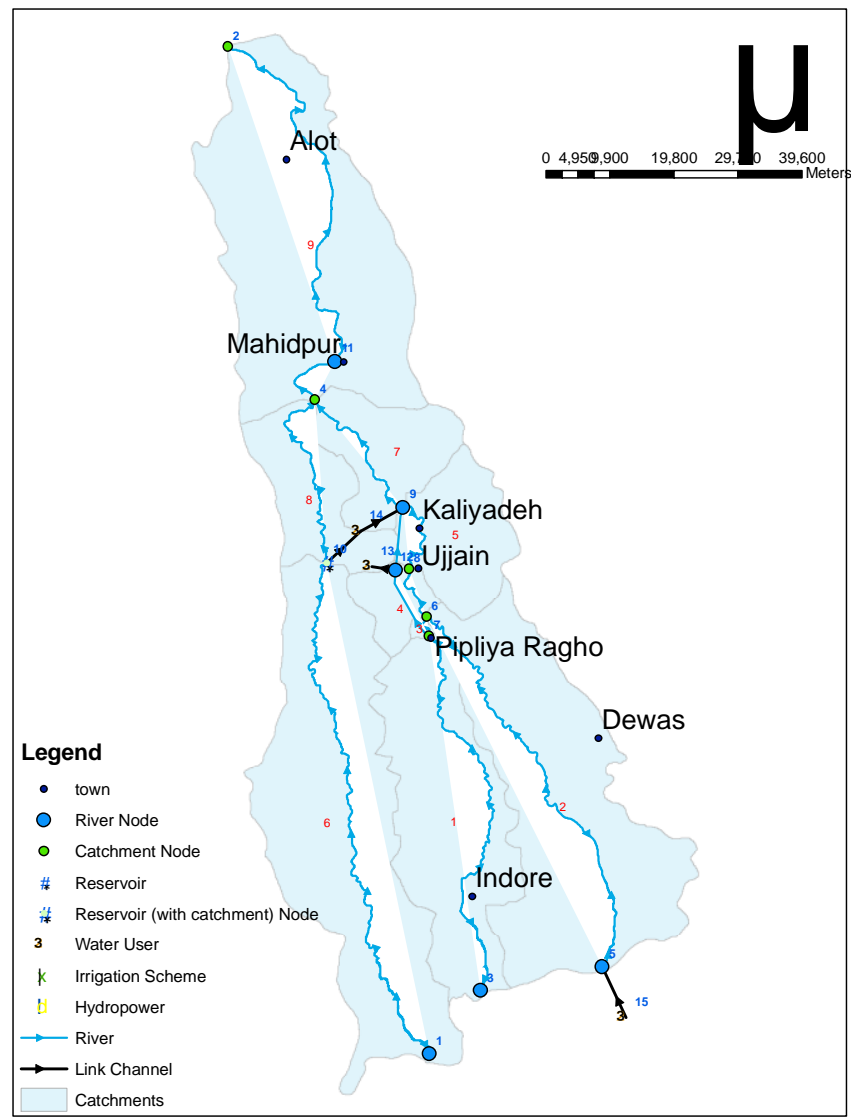

Figure 4: Scenario3: Model with Khan Diversion and Narmada-Shipra Link

\subsection{For Scenario1}

Table 1: Flow in Shipra river at various probability levels (Scenario1)

\begin{tabular}{|l|c|c|l|l|l|l|l|}
\hline \multirow{2}{*}{ Month } & \multicolumn{6}{|l|}{ Probability (\%) } \\
\cline { 2 - 8 } & 70 & 75 & 80 & 85 & 90 & 95 & 100 \\
\hline Jan & 0.00 & 0.00 & 0.00 & 0.00 & 0.00 & 0.00 & 0.00 \\
\hline Feb & 0.00 & 0.00 & 0.00 & 0.00 & 0.00 & 0.00 & 0.00 \\
\hline Mar & 0.00 & 0.00 & 0.00 & 0.00 & 0.00 & 0.00 & 0.00 \\
\hline Apr & 0.00 & 0.00 & 0.00 & 0.00 & 0.00 & 0.00 & 0.00 \\
\hline May & 0.00 & 0.00 & 0.00 & 0.00 & 0.00 & 0.00 & 0.00 \\
\hline Jun & 0.00 & 0.00 & 0.00 & 0.00 & 0.00 & 0.00 & 0.00 \\
\hline Jul & 0.75 & 0.33 & 0.09 & 0.03 & 0.00 & 0.00 & 0.00 \\
\hline Aug & 9.21 & 6.86 & 4.78 & 3.26 & 1.82 & 0.65 & 0.02 \\
\hline Sep & 7.05 & 4.59 & 2.85 & 1.68 & 0.36 & 0.01 & 0.00 \\
\hline Oct & 0.96 & 0.68 & 0.38 & 0.02 & 0.00 & 0.00 & 0.00 \\
\hline Nov & 0.16 & 0.09 & 0.00 & 0.00 & 0.00 & 0.00 & 0.00 \\
\hline Dec & 0.03 & 0.00 & 0.00 & 0.00 & 0.00 & 0.00 & 0.00 \\
\hline
\end{tabular}




\subsection{For Scenario2}

Table2: Flow in Shipra river at various probability levels (Scenario2)

\begin{tabular}{|l|l|l|l|l|l|l|l|}
\hline \multirow{2}{*}{ Month } & \multicolumn{6}{|l|}{ Probability (\%) } \\
\cline { 2 - 8 } & 70 & 75 & 80 & 85 & 90 & 95 & 100 \\
\hline Jan & 0.00 & 0.00 & 0.00 & 0.00 & 0.00 & 0.00 & 0.00 \\
\hline Feb & 0.00 & 0.00 & 0.00 & 0.00 & 0.00 & 0.00 & 0.00 \\
\hline Mar & 0.00 & 0.00 & 0.00 & 0.00 & 0.00 & 0.00 & 0.00 \\
\hline Apr & 0.00 & 0.00 & 0.00 & 0.00 & 0.00 & 0.00 & 0.00 \\
\hline May & 0.00 & 0.00 & 0.00 & 0.00 & 0.00 & 0.00 & 0.00 \\
\hline Jun & 0.00 & 0.00 & 0.00 & 0.00 & 0.00 & 0.00 & 0.00 \\
\hline Jul & 0.75 & 0.35 & 0.09 & 0.03 & 0.00 & 0.00 & 0.00 \\
\hline Aug & 9.21 & 6.86 & 4.78 & 3.30 & 1.82 & 0.65 & 0.02 \\
\hline Sep & 7.05 & 4.59 & 2.85 & 1.68 & 0.29 & 0.01 & 0.00 \\
\hline Oct & 0.96 & 0.68 & 0.38 & 0.02 & 0.00 & 0.00 & 0.00 \\
\hline Nov & 0.11 & 0.06 & 0.00 & 0.00 & 0.00 & 0.00 & 0.00 \\
\hline Dec & 0.02 & 0.00 & 0.00 & 0.00 & 0.00 & 0.00 & 0.00 \\
\hline
\end{tabular}

\subsection{For Scenario3}

Table 3: Flow in Shipra river at various probability levels (Scenario3)

\begin{tabular}{|l|l|l|l|l|l|l|l|}
\hline \multirow{2}{*}{ Month } & \multicolumn{6}{|l|}{ Probability (\%) } \\
\cline { 2 - 8 } & 70 & 75 & 80 & 85 & 90 & 95 & 100 \\
\hline Jan & 1.90 & 1.90 & 1.90 & 1.89 & 1.89 & 1.89 & 1.89 \\
\hline Feb & 1.87 & 1.87 & 1.87 & 1.87 & 1.87 & 1.87 & 1.87 \\
\hline Mar & 1.72 & 1.72 & 1.72 & 1.72 & 1.72 & 1.72 & 1.72 \\
\hline Apr & 1.72 & 1.72 & 1.72 & 1.72 & 1.72 & 1.72 & 1.72 \\
\hline May & 1.72 & 1.72 & 1.72 & 1.72 & 1.72 & 1.72 & 1.72 \\
\hline Jun & 0.98 & 0.48 & 0.13 & 0.04 & 0.03 & 0.00 & 0.00 \\
\hline Jul & 0.88 & 0.48 & 0.13 & 0.04 & 0.00 & 0.00 & 0.00 \\
\hline Aug & 9.33 & 6.86 & 4.83 & 3.31 & 1.83 & 0.70 & 0.02 \\
\hline Sep & 7.06 & 4.58 & 2.89 & 1.72 & 0.29 & 0.01 & 0.00 \\
\hline Oct & 0.96 & 0.69 & 0.40 & 0.03 & 0.00 & 0.00 & 0.00 \\
\hline Nov & 2.00 & 1.95 & 1.89 & 1.89 & 1.89 & 1.89 & 0.00 \\
\hline Dec & 1.93 & 1.89 & 1.89 & 1.89 & 1.89 & 1.89 & 1.89 \\
\hline
\end{tabular}

\section{RESULTS AND DISCUSSIONS}

From table 1 it can be concluded that the river was having flow in monsoon season only. A very little flow was recorded in the months of November and December. There was no flow from January to June. The river was having a highest flow of $9.21 \mathrm{~m}^{3} / \mathrm{s}$ at $70 \%$ probability and $0.02 \mathrm{~m}^{3} / \mathrm{s}$ at $100 \%$ probability in the month of August. At $100 \%$ probability there is no flow in any month except August.

From table 2 (with Khan Diversion) it was observed because of diversion the there was a diversion of water from Khan river in non-monsoon season. But from the table it was observed that there was no flow in non-monsoon period. The flow without diversion and with diversion was almost equal as there was no much flow in non-monsoon season. In the third scenario Narmada-Shipra link was added so that Shipra river could flow throughout the year without deficit and used for different purposes. A flow of $2.5 \mathrm{~m}^{3} / \mathrm{s}$ was transferred from the link. Evaporation and transpiration loses were also added in the model. Table 3 provides the flow details with Narmada-Shipra link. The flow values conclude that river was having flow throughout the year except June and July. In June and July there was no flow because water was added to Shipra river only in nonmonsoon period as rainfall will occur in monsoon period. At $70 \%, 100 \%$ probability a minimum flow of $1.89 \mathrm{~m}^{3} / \mathrm{s}$ was recorded in the month of January and December.

Flow Duration Curves were developed for different months like June and December to show how dependable flow increased at different Scenarios as explained above. The graphs were shown in figures 5 and 6.

In both the graphs the flow due to Narmada-Shipra link was more when compared to other two. Scenario1 (normal flow) was having more flow than Scenario2 (khan Diversion) because of diversion of flow.

The graph showing water availability in Shipra river under different Scenario flow conditions at $90 \%$ probability is shown in figure 7 . The monthly flow volumes increased considerably as shown in the figure. The variation was shown between normal flow condition and flow with Narmada-Shipra link. Acceptable increase of flow was there in case of Narmada-Shipra link.

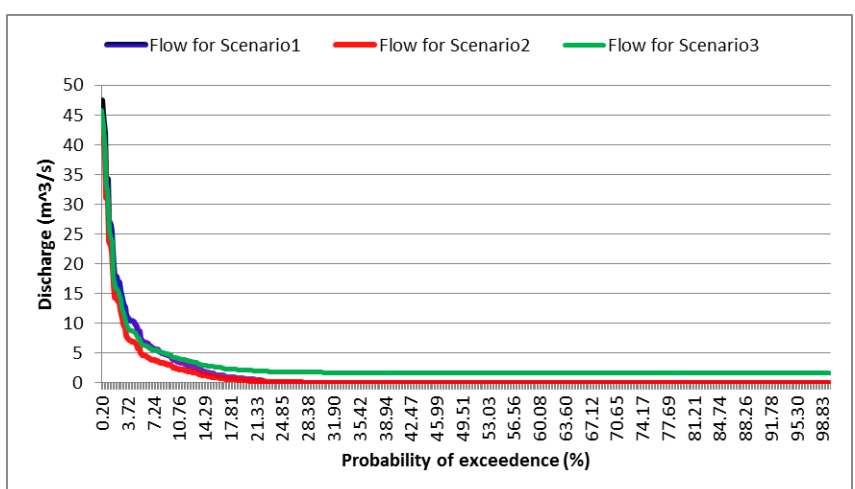

Figure 5: Flow Duration Curve for three Scenarios in the month of June

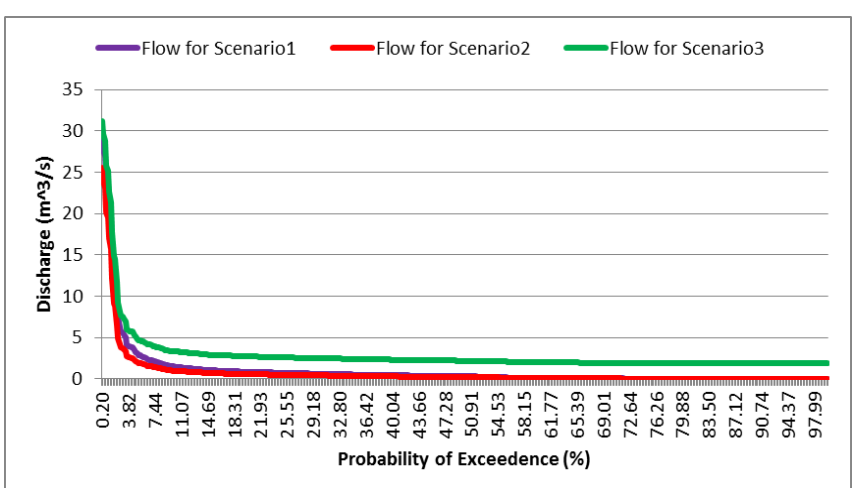

Figure 6: Flow Duration Curve for three Scenarios in the month of December 


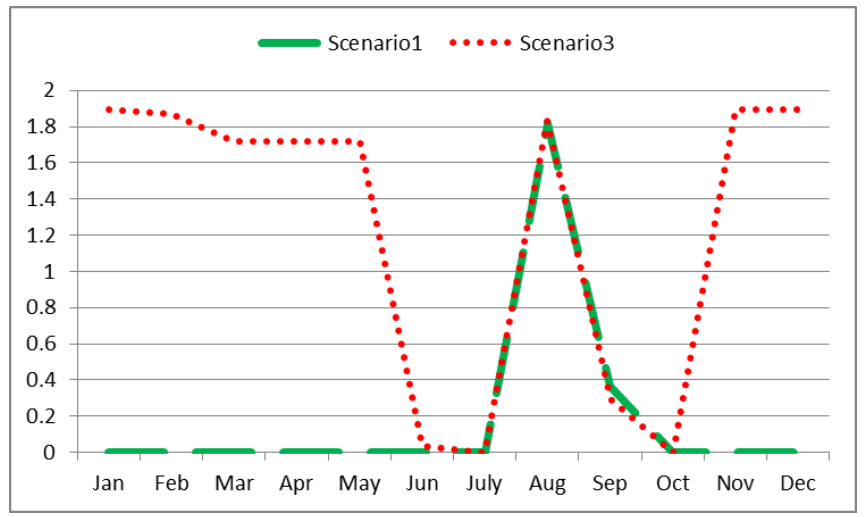

Figure 7: Water availability is Shiprariver between Normal flow and flow with Narmada-Shipra link.

\section{CONCLUSION}

From the above analysis it is evident that Mike Basin Model is working efficiently with accuracy to assess the water availability, dependable flows at various locations at various probability levels under changing hydrological conditions such as Khan diversion and Narmada-Shipra link in Shipra river basin. The NAM rainfall runoff model was found suitable for the Shipra basin and used successfully in other ungauged sub-basins of the Shipra for simulation of runoff. Water availability analysis is carried out at Ujjain which concludes that the Shipra river has an ephemeral type of flow i.e. having flow during monsoon period only and no flow during lean period. In order to meet the various water demands of Shipra and especially to make assure water availability during Kumbh and other holy baths in the river, various hydrological scenarios are tested in Mike Basin model. The analysis suggested that Khan river diversion would successfully be used to divert polluted water to assure better water quality at Ujjain. However, the water availability was found reduced at Ujjain due to Khan diversion. To overcome this situation, the Narmada-Shipra link was found to be the best solution to improve water availability in the river. The analysis suggested that the water availability at Ujjain due to Narmada-Shipra link was increased significantly. The water availability at Ujjain has been found increased and the river was observed having sufficient dependable flow at various probabilities even at $100 \%$ probability. The water supply from Gambhir dam to Ujjain city was found sufficient to meet its domestic water demand. However, the severe water deficit was observed at Ujjain due to severe drought condition in year 2000. The Mike Basin scenario model was tested and analyzed to check how to meet such water deficit challenges.

Finally Water Availability Analysis was made at Ujjain city from 1990 to 2006. Monthly calculations were made and represented in the form of tables for all the three scenarios. The results conclude that for the first two scenarios there was no flow in non-monsoon period. But after adding Narmada-Shipra link there was a minimum flow of $1.72 \mathrm{~m}^{3} / \mathrm{s}$ in river throughout the non-monsoon period.

\section{REFERENCES}

[1]. Pandey, R.P. and Ramasastri, K.S. "Estimation of lean season water availability in streams with limited data". Institute of Engineers (I) Journal, Vol. 84, November 2003, 149-152.

[2]. Chang, M. and Boyer, D.G. "Estimates of low flow using watershed and climatic parameters". Water Resources Research, vol 13, no 6, 1977, 977-1001.

[3]. Clausen B and Pearson C P. "Regional frequency analysis of annual maximum streamflow drought". Journal of Hydrology, vol 173, 1995, 111-130.

[4]. Galkate, R.V., Thomas, T., and Jaiswal, R. K. "Low flow analysis in Kharun river of Chhattisgarh State", International Workshop on River Management (IWRM), Dec 14-16, 2010, New Delhi.

[5]. DHI. 2003. MIKE BASIN: MIKE BASIN Training Mannual, Danish Hydraulic Institute, Copenhagen,Denmark. 